Monika Wiśniewska-Kin

https://doi.org/10.26881/pwe.2018.42.06

ORCID: 0000-0002-6300-8435

Uniwersytet Łódzki

monika.kin@uni.lodz.pl

\title{
„Uwspólnione” tworzenie sensu w interakcji dziecka z dorosłym
}

\section{Summary}

\section{Sharing of meaning in the interaction of a child with an adult}

This article demonstrates the results of the educational project "stimulating children's thinking" carried out in some primary schools in a metropolitan environment (Lodz, Poland). The aim of the study was to identify the ways of understanding the concept of community by 9-10-year old children. In the didactical intervention operations designed, the research data came from participated observation, focus interview, and children's production analysis (graphical visualization, pairedassociate learning tasks and tests of unfinished tasks). Based on my research, I see the need for triggering the cognitive activity of pupils in conditions that ensure the development of conceptual systems. Moreover, the findings suggest the need of broader understanding of educational environments in Polish educational culture.

Keywords: understanding of concepts, strategies to develop children's ways of understanding and interpreting concepts, culture of education

Słowa kluczowe: rozumienie pojęć, strategie rozwoju dziecięcych sposobów rozumienia i interpretowania pojęć, kultura edukacji

Omówione w artykule założenia teoretyczne, wyprowadzam ze społeczno-kulturowych teorii wzajemności: interakcyjnej orientacji w konstruowaniu znaczeń (scaffolding) Lwa S. Wygotskiego, uzgadniania znaczeń Jerome’a S. Brunera, epizodów wspólnego zaangażowania H. Rudolpha Schaffera, społecznych interakcji typu tutoring Davida Wooda, doświadczenia upośrednianego uczenia się (mediated learning experience) Reuvena Feuersteina i Pniny S. Klein, a także intersubiektywnego uczenia się przez podzielanie znaczeń (sharing of meaning) Ragnara Rommetveita. Pozwalają one rozpoznać problematykę poświęconą procesowi usensawniania, czyli uświadamiania sobie otaczającej rzeczywistości i nadawania jej znaczeń z perspektywy dziecka, w warunkach upośrednionego uczenia się.

Wymienione koncepcje mimo istotnych różnic pozostają wzajemnie koherentne - dopełniają i pogłębiają refleksję o edukacyjnych możliwościach wzajemnego uczenia się. Skłaniają do stawiania pytania o to, w jaki sposób zaprojektować zdarzenia edukacyjne, by doświadczenia szkolne ucznia rozbudzały poznawczą motywację, gotowość stawiania niekonwencjonalnych pytań i nieschematycznych rozwiązań? 
Badanie procesów poznawczych na gruncie tych teorii doprowadziło do następujących ustaleń: (1) Wśród sposobów pozyskiwania wiedzy o rzeczywistości znaczącą rolę odgrywa doświadczanie sytuacji edukacyjnych, w których dorosły jako mediator oswaja dzieci $\mathrm{z}$ utrwalonym w kulturze i uwspólnionym $\mathrm{w}$ wiedzy społecznej stosunkiem do rzeczywistości. (2) Proces podzielania znaczeń nie jest narzucony przez uczestników interakcji, ale zostaje wspólnie wypracowany w długotrwałych próbach negocjowania. Wynegocjowany system znaczeń nigdy nie pokrywa się całkowicie z osobistymi znaczeniami wszystkich uczestników interakcji, jest raczej dialogiem ze stosowanym wcześniej przez dzieci sposobem rozumienia świata. Koncepcje te doprowadziły do odmiennego rozumienia wiedzy dziecka i mechanizmów jej rozwoju, jak również procesu uwspólnionego tworzenia sensu.

\section{Strategia badawcza projektowania procesu uwspólnionego tworzenia sensu}

W podjętej próbie zrekonstruowania zewnętrznych warunków wyzwalających uczniowskie możliwości w zakresie tworzenia sensów, odwołałam się do koncepcji badań jakościowych. Jakościowe podejście pomogło dostrzec potoczne interpretacje rzeczywistości z dziecięcego punktu widzenia, oddające jego sposób postrzegania i rozumienia definiowanych pojęć. W badaniach trzecioklasistów najwłaściwsza okazała się koncepcja definiowania kognitywnego z wpisaną adaptacyjną racjonalnością potoczną (Anusiewicz, Nieckula 1992). Otwarta formuła definicji kognitywnej pozwala bowiem szczegółowo określić, nie tylko utrwalone w systemie językowym typowe cechy i funkcje obiektu, ale też uwarunkowane kulturowo cechy konotacyjne (Bartmiński 2007). Tak rozumiana definicja dziecięca postrzegana jest jako zindywidualizowane opowiadanie świata zakorzenione w racjonalności potocznej (Maćkiewicz 2000; Boniecka 2001). „Zdroworozsądkowa” wiedza potoczna zyskuje nową rangę: nie można jej bagatelizować ani infantylizować, wprost przeciwnie, trzeba ją rekonstruować i wydobywać z zasobów języka naturalnego, stanowiącego składnik treściowy definicji kognitywnej (Boniecka, Grabias 2007).

Ponieważ interakcyjne wyzwalanie sensów dziecięcych znaczeń, pozwala dokładniej opisać zdolności poznawcze dzieci, w badaniach szczególną uwagę zwróciłam na najwcześniej zdobywaną przez dzieci ${ }^{1}$ umiejętność kategoryzowania jednych pojęć na podstawie innych oraz rozpoznawania podobieństw i różnic między definiowanymi pojęciami (Langacker 1995). Przyjęłam zatem, że badanie będzie miało zarówno cel teoretyczno-poznawczy (czyli analizę dziecięcych predyspozycji w zakresie nadawania sensu pojęciom i ich kategoryzowania), jak i praktyczny (czyli refleksję, jak można usprawniać dziecięcy proces tworzenia sensu oraz kiedy zewnętrzna stymulacja jest najbardziej efektywna).

Aby ustalić, jak dzieci nadając sens pojęciom podejmują próby ich kategoryzowania, pojęcia zestawiałam w pary antonimiczno-synonimiczne. W tekście opisuję parę pojęć abstrakcyjnych wspólnota vs. zbiorowość. Zdecydowałam się na wybór tych pojęć, po-

1 Umiejętność kategoryzowania na zasadzie podobieństwa i różnicy traktowana jest w badaniach Johna McShane'a jako fundamentalna. Por. J. McShane, Cognitive Development: An Information Processing Approach, Oxford 2001, s. 133. 
nieważ dostrzegam w ich zestawieniu ciekawe zależności semantyczne. Mimo istotnych różnic, istnieje między nimi pewne podobieństwo: współbycie zarówno we wspólnocie jak iw zbiorowości wymaga poświęcenia jakiejś cząstki wolności, zaś dobrowolne ograniczanie wolności wiąże się z dążeniem do scalania grupy, natomiast scalaniu grupy towarzyszy odseparowanie od innych.

W badaniach dążyłam do wydobycia dziecięcych umiejętności w zakresie ujmowania relacji podobieństw i różnic między pojęciami oraz różnicowania sensu każdego z tych pojęć przez podkreślenie cech identyfikujących. W tym celu w dydaktycznych działaniach interwencyjnych, zadbałam o intencjonalną kreację warunków dydaktycznych (Klus-Stańska 2010: 131-132). W powszechnych szkołach podstawowych, w którym prowadzone były badania, podjęta problematyka była nieprzewidziana i nieproponowana przez program i podręczniki szkolne.

Materiał do badań zapewniły zajęcia edukacyjne, które organizowałam w ramach obserwacji uczestniczącej². Występując $\mathrm{w}$ roli interpretacyjnie zaangażowanego obserwatora-jako-uczestnika (Angrosino 2010), wykorzystałam zbiorowe i indywidualne formy pracy z dziećmi, dzięki którym obserwacją mogłam objąć czynności uczniów, a także skutki tych czynności (przede wszystkim werbalne reprezentacje i plastyczne konkretyzacje). Badania zostały przeprowadzone z uczniami klas trzecich (łącznie stu dwudziestu uczniów), szkół podstawowych zlokalizowanych w środowisku wielkomiejskim. Próbę badawczą stanowili trzecioklasiści ze względu na dobrze rozwinięte kompetencje językowe i komunikacyjne, które ułatwiają eksplikację myśli. Badania zostały przeprowadzone w miejscach, które zapewniają dzieciom naturalne warunki uczenia się, w typowych szkołach podstawowych ${ }^{3}$.

Istotną przesłanką uwspólnionego tworzenia sensów było systematyczne oraz powolne wyzwalanie dziecięcego namysłu. Proces rozpoznawania dziecięcych sensów następował w sekwencjach, obejmujących poszczególne wątki problemowe: od najprostszych do strukturalnie złożonych. Tworzywem służącym do uruchamiania tego procesu były: dziecięca przedwiedza, wybrane teksty literackie oraz książki obrazkowe (picture book). $\mathrm{W}$ artykule opis sprowadzę jedynie do ukazania strategii aktywizowania uczniowskiej przedwiedzy (por. Mietzel 2003).

\section{Aktywizacja uczniowskiej przedwiedzy w procesie uwspólnionego tworzenia sensu}

Konceptualizacja aspektu wspólnotowego rozpoczęła się od rozmowy na temat podobieństw i różnic między wspólnotą a zbiorowością, sprowokowanej pytaniami: Z czym

\footnotetext{
2 W dwuletnim okresie gromadzenia materiału badawczego uczestniczyły moje seminarzystki: M. Jaszczuk, D. Kaczmarek, M. Kalińska, P. Korczowic, E. Kowalska, M. Kwasek, A. Pajnowska. Cały etap gromadzenia danych zamknął się w okresie dwóch lat (w roku akademickim 2016/2017 i 2017/2018).

3 Wybrane do badań szkoły to: Katolicka Szkoła Podstawowa im. Błogosławionych Dzieci z Fatimy w Łodzi, Szkoła Podstawowa nr 71 w Łodzi, Szkoła Podstawowa nr 149 w Łodzi.
} 
wam się kojarzą wyrazy wspólnota vs. zbiorowość? Kiedy i od kogo słyszeliście te wyrazy? Spróbujcie sobie przypomnieć, z jakimi wyrazami łączą się te pojęcia?

$\mathrm{Z}$ wypowiedzi wynikało, że uczniowie dysponując wieloma schematami przedwiedzy, kierowali uwagę raczej na określone szczegóły wydarzeń towarzyszących członkom wspólnoty i zbiorowości, niż na cechy identyfikujące dwóch porównywanych pojęć: „możemy wspólnie dzielić się pracą, wspólnie robić zakupy, razem grać na komputerze, zagrać mecz, można wspólnie spędzić święta". Wyszukując w pamięci wyjaśnienia, które można byłoby zastosować dla tych pojęć, korzystali często z wyrażeń tautologicznych, ujawniając raczej potoczne rozumienie porównywanych pojęć: „,wspólnota to wspólne robienie czegoś”, „wspólnota, czyli coś wspólnego: mojego i twojego”, „wspólny to jak jedna rzecz należy do kogoś jednego i do kogoś innego”, zbiorowość natomiast to „to co się zbiera”, „zbiory czegoś, np. kwadratów”. Często zdarzało się, że nakładając na siebie zakresy znaczeniowe tych pojęć, nie zwracali uwagi na ich rozbieżności: „we wspólnocie i w zbiorowości każdy jest tak samo ważny”, ,we wspólnocie najważniejsze są dobre relacje, zgoda, przyjaźń a w zbiorowości możliwość bycia razem". Umocowaniem dla takich sposobów werbalizacji były stworzone przez dzieci wizualizacje graficzne, które ujawniły źródła dziecięcej przedwiedzy.

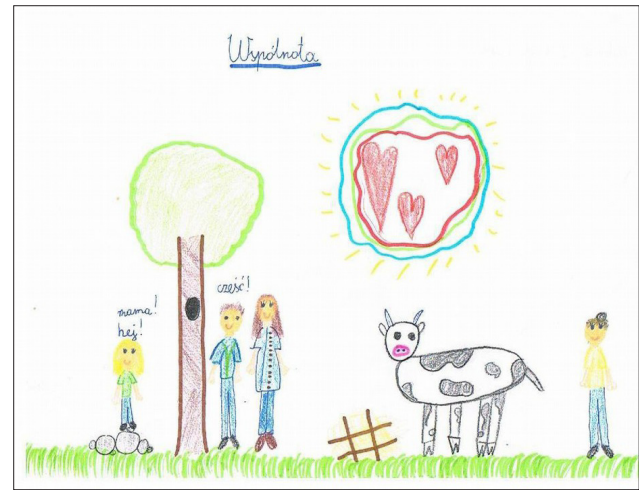

Rys. 1. Konkretyzacja plastyczna wspólnoty

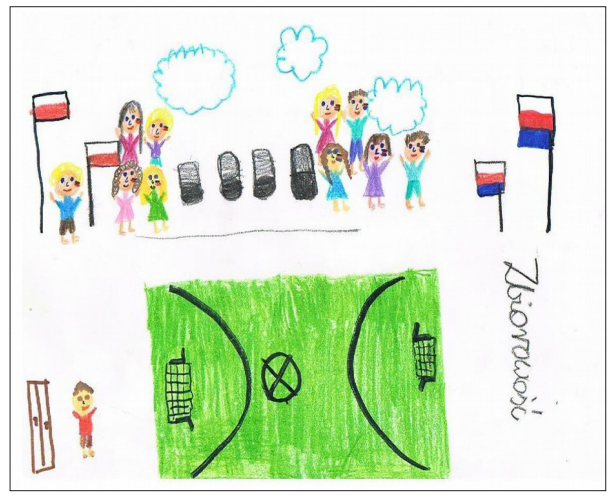

Rys. 2. Konkretyzacja plastyczna zbiorowości

\section{Opór przeciwko zmianom pojęciowym}

W możliwie szerokim zakresie, uwzględniając werbalne i obrazowe reprezentacje uczniowskiego przedrozumienia, zainicjowałam rozmowę o pracach, które powstały. Te dwie zróżnicowane formy ludzkiej więzi wyzwoliły w dzieciach dominujące wrażenie miłej łagodności, wesołości i bezpieczeństwa. Takie rozumienie potwierdzają atrybuty sielskiego klimatu: „chmurki, słonko, trawka, drzewka, krówka, wesoła rodzina”, zwizualizowane przez użycie pastelowych barw.

Uobecnione w wypowiedziach werbalnych i konkretyzacjach plastycznych przedrozumienie trzecioklasistów, stało w sprzeczności ze znaczeniami, które chciałam wyko- 
rzystać w zaprojektowanym przez siebie procesie uwspólnionego konstruowania znaczeń. Mój sceptycyzm wzbudziły - w gruncie rzeczy powierzchowne - natura i źródło przeżyć, które wyrastają z przedstawionych sytuacji (sielski krajobraz dla niczym niezmąconych relacji międzyludzkich).

Zaproponowane oddziaływania edukacyjne ujawniły więc istnienie dwóch alternatywnych rodzajów rozumienia: badacza i uczniów. Aby zachęcić uczniów do ponownego przedyskutowania zalet i wad przedstawionych objaśnień, rozmowę ukierunkowałam na sensy związane z wszystkimi emocjami, jakich dostarcza bycie we wspólnocie i w zbiorowości. Rozważania zogniskowaliśmy wokół wątku poświęconego wspólnocie poddawanej próbie: najgłębsze, najtrwalsze uczucia i najsilniejsze więzi rodzą się ze zdarzeń wyjątkowych i trudnych, które budzą emocje ambiwalentne i niepokojące, ale są faktyczną „szkołą uczuć” i wykuwają charakter.

\section{Przygotowanie rusztowania}

Rozbieżność dotycząca zakresu znaczeniowego pojęć, przez psychologów określana jako „zbliżone dopasowanie” (approximate fit) (Appleton 1997), zmobilizowała mnie do stworzenia takiej sytuacji edukacyjnej, w której uczniowie będą mogli podjąć wysiłek związany z rozszerzeniem znaczenia pojęć wspólnota vs. zbiorowość. Kolejna interakcja wyrastała zatem z konieczności pogłębienia dotychczasowych przemyśleń.

Uczniowie uzmysłowili sobie istotne elementy swojego przedrozumienia w trakcie kategoryzowania zróżnicowanych fotografii wspólnot (rodzinnej, rówieśniczej, sąsiedzkiej, katolickiej) i zbiorowości (tłumu kibiców, uczestników koncertu, zgromadzenia w manifestacji, thumu w przestrzeni publicznej: w sklepie, na przystanku autobusowym). Zainicjowany tym ćwiczeniem dziecięcy namysł skupiał się wokół elementarnych doświadczeń uczniów oraz osobistych sądów i przekonań, które wcześniej uczniowie często przyjmowali bezrefleksyjnie. Zobrazowane autentyczne sytuacje zaktywizowały dziecięce rozumienie. Dzieci z łatwością przyporządkowały do wspólnoty ilustracje rodziny, przyjaciół, zaś do zbiorowiska ilustracje thumu na przystanku, koncercie czy w centrum handlowym. Głębszy namysł wywołały zdjęcia ludzi protestujących i modlących się. Zdaniem dzieci nie tylko miejsca (szerzej przestrzenie), ale przede wszystkim potrzeby scalają poczucie wspólnotowości. Ich opis pomógł dzieciom zrozumieć, że do zawiązania wspólnoty konieczne jest doświadczenie poczucia bliskości w bezpiecznym miejscu. Równie ważne były dla dzieci okoliczności towarzyszące zawiązywaniu i umacnianiu więzi wspólnotowych. Dzieci uświadomiły sobie, że ludzi protestujących, mimo braku bliskości emocjonalnej, łączy konieczność wynikająca ze wspólnego bycia razem. Kluczowa w procesie usensawniania tych pojęć okazała się wypowiedź jednego z uczniów: „dla mnie to że jesteśmy sobie bliscy jest ważniejsze od tego, gdzie się spotkamy i po co". 


\section{Aktywne przetworzenie nowych informacji}

Dziecięcy namysł nad zrekonstruowanym przez dzieci sensem wspólnotowości uruchomił działania o charakterze przekładu intersemiotycznego. Zapis ideograficzny ułatwił uczniom przekroczenie dosłowności i wyzwolił komentarze oparte na szerszych skojarzeniach, związanych z kształtem i kolorem. Zajęcia zaczęliśmy od wizualizacji. Ze schematów postaci kobiecych i męskich, dzieci próbowały symbolicznie stworzyć wspólnotę i zbiorowość. W rozumieniu dzieci we wspólnocie: wszyscy się potrzebują, wybrali się nawzajem, są tak samo ważni, brak któregokolwiek z członków wspólnoty „burzy” spokój, ład i harmonię (dzieci obrazują to rozumienie przez nieodwracalne przerwanie wspólnotowego kręgu, którego ponowne złączenie wymaga czasu). Zupełnie inne znaczenia wydobyli z wizualizacji zbiorowości: uczestnicy zbiorowości zebrali się ze względu na okoliczności, sfera wzajemnych relacji nie jest oparta na uczuciach (członkowie zbiorowiska nie są ze sobą połączeni, są „,razem, ale osobno”), odejście członka zbiorowości jest niezauważalna.

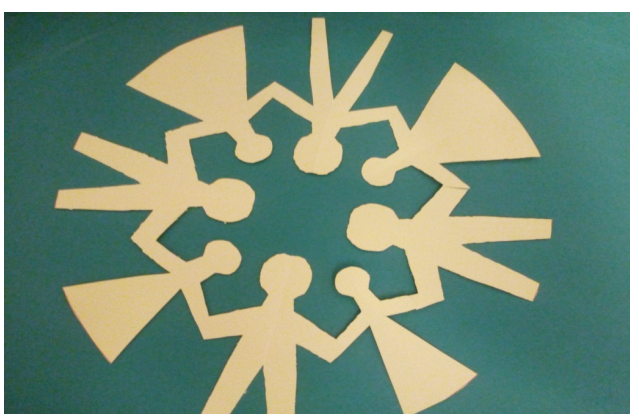

Rys. 3. Konkretyzacja plastyczna wspólnotowego kręgu

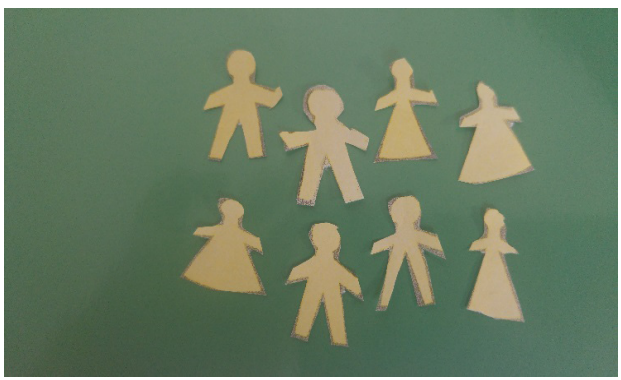

Rys. 5. Konkretyzacja plastyczna zbiorowości

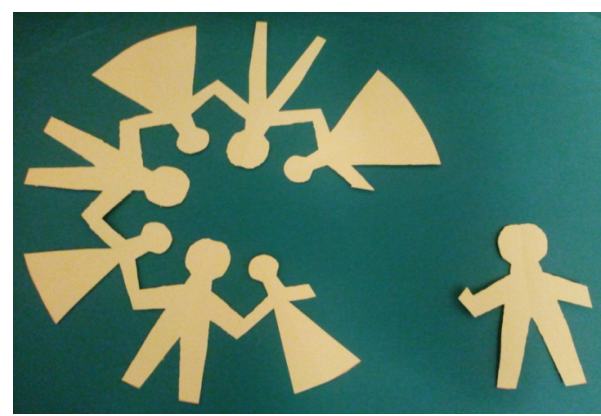

Rys. 4. Konkretyzacja plastyczna rozpadu wspólnoty

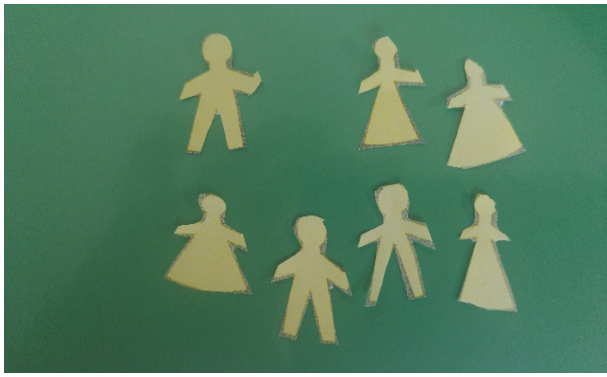

Rys. 6. Konkretyzacja plastyczna niepełnej zbiorowości

Ćwiczenie z zastosowaniem symbolicznej wizualizacji wzmocniło uczniowskie wysiłki, mające na celu głębsze zrozumienie podjętego obszaru problemowego i stworzyło okazję do wzajemnego przekazywania sobie w zrozumiałej formie swoich wyobrażeń i odkryć. Zaktywizowało też uczniów do wysiłku sensownego wyjaśnienia nowych do- 
świadczeń, a także towarzyszących mu w tym odczuć, w wyniku nadawania kolorów schematycznym figurom: „moje figurki mają różne kolory (czarne, czerwone, żółte, niebieskie), bo we wspólnocie niektórzy są smutni, radośni, skromni, spokojni, zmartwieni i złośliwi”. Działania na symbolach o odmiennych walorach kolorystycznych (jasne - ciemne, ciepłe - zimne, łagodne - zdecydowane) umacniały i ugruntowywały refleksję nad wywołaną problematyką. W świadomości dzieci pojawiły się nowe sensy: każda wspólnota poddawana jest próbom: wspólnocie zagrażają smutek, zmartwienie i złośliwości. Do utrzymania głębokich więzi nieodzowne są radość, skromność i spokój. Dzieci odkrywają więc, że dzięki cechom charakteru wszystkich członków wspólnoty udaje się przezwyciężyć nieodzownie pojawiające się trudności.

\section{Przeżycie i przezwyciężenie konfliktu poznawczego}

Uwspólniona konceptualizacja pojęć abstrakcyjnych wykazała, że istnieje znaczny potencjał zdolności poznawczych dzieci w zakresie kategoryzowania. Przygotowane „rusztowanie" wyzwoliło dziecięce możliwości w zakresie wychwytywania podobieństw i różnic między zawartością pojęciową. Zestaw cech identyfikujących porównywane pojęcia przedstawiam $w$ ujęciu tabelarycznym ( $w$ zestawieniu uwzględniam najbardziej reprezentatywne wypowiedzi: frekwencja $\geq 10$ ).

Tabela 1. Sposoby kategoryzacji pojęcia wspólnota z uwzględnieniem liczby respondentów i wypowiedzi (w\%)

\begin{tabular}{|c|c|c|c|c|}
\hline Kategorie & N resp. & \% resp. & N odp. & \% odp. \\
\hline \multicolumn{5}{|c|}{ Jaka jest/jaka może być/jaka powinna być wspólnota (W) vs. zbiorowość (Z)? } \\
\hline miła & 21 & 17,5 & 21 & 1,8 \\
\hline dobra & 16 & 13,3 & 16 & 1,4 \\
\hline przyjazna (13);przyjacielska (3) & 16 & 13,3 & 16 & 1,4 \\
\hline odpowiedzialna & 16 & 13,3 & 16 & 1,4 \\
\hline różnorodna & 11 & 9,2 & 11 & 1,0 \\
\hline pomocna & 11 & 9,2 & 11 & 1,0 \\
\hline przypadkowa & 28 & 23,3 & 28 & 2,5 \\
\hline wielka/ogromna/duża & 14 & 11,7 & 14 & 1,2 \\
\hline bezcelowa & 12 & 10,0 & 12 & 1,1 \\
\hline obca & 11 & 9,2 & 11 & 1,0 \\
\hline nietrwała & 11 & 9,2 & 11 & 1,0 \\
\hline obojętna & 10 & 8,3 & 10 & 0,9 \\
\hline \multicolumn{5}{|c|}{ Co jest najważniejsze we wspólnocie vs zbiorowości? } \\
\hline \multirow{6}{*}{$\begin{array}{r}\text { miłość/uczucia } \\
\text { więzi } \\
\text { wspólny cel } \\
\text { przyjaźń } \\
\text { człowiek/osoby/ludzie } \\
\text { szacunek }\end{array}$} & 37 & 30,8 & 37 & 3,2 \\
\hline & 27 & 22,5 & 27 & 2,4 \\
\hline & 22 & 18,3 & 22 & 1,9 \\
\hline & 19 & 15,8 & 19 & 1,7 \\
\hline & 16 & 13,3 & 16 & 1,4 \\
\hline & 12 & 10,0 & 12 & 1,1 \\
\hline
\end{tabular}


Tabela 1. cd.

\begin{tabular}{|c|c|c|c|c|}
\hline Kategorie & N resp. & \% resp. & N odp. & \% odp. \\
\hline wydarzenie & 28 & 23,3 & 28 & 2,5 \\
\hline ludzie & 15 & 12,5 & 15 & 1,3 \\
\hline miejsca & 15 & 12,5 & 15 & 1,3 \\
\hline zainteresowania & 13 & 10,8 & 13 & 1,1 \\
\hline sytuacja & 13 & 10,8 & 13 & 1,1 \\
\hline czas & 10 & 8,3 & 10 & 0,9 \\
\hline \multicolumn{5}{|c|}{ Kto może stworzyć wspólnotę vs zbiorowość? } \\
\hline rodzina & 38 & 31,7 & 38 & 3,3 \\
\hline przyjaciele/ przyjaźń & 35 & 29,2 & 35 & 3,1 \\
\hline dorośli & 11 & 9,2 & 11 & 1,0 \\
\hline dzieci & 11 & 9,2 & 11 & 1,0 \\
\hline przypadkowi ludzie/tłum & 35 & 29,2 & 35 & 3,1 \\
\hline dorośli & 16 & 13,3 & 16 & 1,4 \\
\hline dzieci & 11 & 9,2 & 11 & 1,0 \\
\hline \multicolumn{5}{|c|}{ Co można robić we wspólnocie vs zbiorowości? } \\
\hline pomagać & 31 & 25,8 & 31 & 2,7 \\
\hline kochać & 22 & 18,3 & 22 & 1,9 \\
\hline bawić się & 20 & 16,7 & 20 & 1,8 \\
\hline wspierać się & 13 & 10,8 & 13 & 1,1 \\
\hline być obok & 15 & 12,5 & 15 & 1,3 \\
\hline kibicować & 13 & 10,8 & 13 & 1,1 \\
\hline protestować & 12 & 10,0 & 12 & 1,1 \\
\hline modlić się & 11 & 9,2 & 11 & 1,0 \\
\hline \multicolumn{5}{|c|}{ Czego nie można robić we wspólnocie vs zbiorowości } \\
\hline kłócić się & 35 & 29,2 & 35 & 3,1 \\
\hline źle traktować innych & 24 & 20,0 & 24 & 2,1 \\
\hline obrażać się & 22 & 18,3 & 22 & 1,9 \\
\hline kłamać & 18 & 15,0 & 18 & 1,6 \\
\hline kraść & 13 & 10,8 & 13 & 1,1 \\
\hline bić się & 12 & 10,0 & 12 & 1,1 \\
\hline przezywać się & 10 & 8,3 & 10 & 0,9 \\
\hline źle traktować innych & 22 & 18,3 & 22 & 1,9 \\
\hline bić się & 11 & 9,2 & 11 & 1,0 \\
\hline \multicolumn{5}{|l|}{ Po co istnieją wspólnoty vs zbiorowości? } \\
\hline żeby się kochać & 12 & 10,0 & 12 & 1,1 \\
\hline pomagać sobie & 12 & 10,0 & 12 & 1,1 \\
\hline szanować się, & 12 & 10,0 & 12 & 1,1 \\
\hline wspierać się & 12 & 10,0 & 12 & 1,1 \\
\hline dla rozrywki & 11 & 9,2 & 11 & 1,0 \\
\hline żeby się poznawać & 10 & 8,3 & 10 & 0,9 \\
\hline żeby nie być samemu & 8 & 6,7 & 8 & 0,7 \\
\hline suma odpowiedzi & & & 942 & 100,0 \\
\hline liczba respondentów & 120 & & & \\
\hline
\end{tabular}


Zwerbalizowany aspekt wspólnotowy dzieci sprowadzają do wybranych obszarów: rodzaje więzi wspólnotowych, cechy zespalające i rozbijające wspólne bycie razem oraz formy aktywności. Z zestawień ilościowych wynika, że wysokie pozycje listy częstotliwości zdecydowanie różnicują wspólnotę vs. zbiorowość w aspekcie jakości: wspólnota jest miła, dobra, przyjacielska, odpowiedzialna, zbiorowość zaś przypadkowa, wielka, bezcelowa, obca, nietrwała oraz w aspekcie działania: we wspólnocie można pomagać, kochać, bawić się, wspierać natomiast w zbiorowości być obok, kibicować, protestować. Wyraźne różnice ujawniają się też w obszarze wartościowania: we wspólnocie najważniejsze są: uczucia, więzi, wspólny cel, przyjaźń, człowiek, szacunek, zaś w zbiorowości: wydarzenie, miejsce, ludzie, zainteresowania, sytuacje. Na pierwszych miejscach listy asocjacji plasują się uszczegółowienia rodzajów więzów wspólnotowych (dla wspólnoty) oraz okoliczności zewnętrzne towarzyszące zbiorowości (wydarzenia, miejsca, sytuacje). Zawartość pojęciową różnicują też odpowiedzi dotyczące członków więzi wspólnotowych: rodzina, przyjaciele vs. przypadkowi ludzie, chociaż w przypadku tego obszaru znaczeniowego dzieci dostrzegają też pewne podobieństwa: wspólnotę i zbiorowość tworzą dorośli i dzieci. Podobne relacje podobieństw i różnic między pojęciami dzieci dostrzegają przy omawianiu negatywnej odmiany działania w rodzinie. Do negowanych czynności dzieci zaliczają kłócenie się, złe traktowanie innych, obrażanie się oraz bicie. W odpowiedziach na ostatnie pytanie, dotyczące powodów istnienia wspólnoty i zbiorowości, powtarzają te kategorie, które występowały we wcześniej postawionych pytaniach. Definiując zasadność istnienia wspólnoty podkreślają po raz kolejny motyw miłości (tym razem na pozycji pierwszej) oraz aspekt pomagania sobie, szanowania się $i$ wspierania się (na tej samej pozycji na liście częstotliwości) oraz motyw ludyczny (dla rozrywki, żeby się poznać) w przypadku celowości istnienia zbiorowości.

\section{Wspólnotowość w dyskursie szkolnym}

Rekonstrukcja uwspólnionego tworzenia sensu w interakcji dziecka z dorosłym, zmierzała do ustalenia, w jaki sposób można pogłębić uczniowski namysł nad zespalaniem i umacnianiem wspólnoty, stojącej współcześnie przed koniecznością zajęcia stanowiska wobec innego (sprowokowanej chociażby narastającym problemem imigracji).

Projekt uświadomił też znaczenie interwencji dydaktycznej usprawniającej dziecięcy proces tworzenia sensu. Po pierwsze, intencjonalność działania i wzajemność wymiany, sprowadzająca się do organizowania wspierających sytuacji edukacyjnych oraz wypracowanie skutecznych strategii w czasie interakcji z dzieckiem. Po drugie, upośrednianie znaczenia, czyli wykazywanie wrażliwości na dziecięce sposoby postrzegania i interpretowania rzeczywistości, a także przejawianie gotowości do rozumienia wielogłosowych, wewnętrznie zdialogowanych punktów widzenia dziecka. Po trzecie, wspólne ustalenie celu działania i wytrwałe dążenie do niego, a także podtrzymywanie uczniowskiego zorientowania na cel. Po czwarte, wzmocnienie poczucia kompetencji oraz stymulowanie dziecięcej świadomości, ciekawości i zainteresowania działaniem. Po piąte, wspieranie 
samodzielnych prób działania oraz regulowanie dziecięcych zachowań, przez uwrażliwianie na krytyczne momenty w procesie rozwiązywania zadania. Po szóste, czuwanie nad uczniowskimi stanami emocjonalnymi, a także wyzwalanie pozytywnych nastawień.

Dydaktyczne działania interwencyjne uświadomiły też, że uczniowie mając silne skłonności do interpretacji „niezgodnych” z oczekiwaniami zdarzeń, które odpowiadają ich przedwiedzy, nie przeżywają żadnego konfliktu poznawczego, żadnej niezgodności między wiedzą a tym, czego doświadczyli. Asymilując jedynie materiał, nie ujawniają gotowości do poszukiwania alternatywnych odpowiedzi. Działalność wychowawcza powinna zatem zostać sprowadzona do podwójnej interwencji: w rzeczywistość indywidualną (w osobisty świat dziecka, jego obrazy świata i samego siebie oraz ukryte teorie wyjaśniające funkcjonowanie świata), a także w rzeczywistość społeczną (w utrwalony w kulturze, zakorzeniony i uwspólniony w wiedzy społecznej świat znaczeń). Uzgadniana społecznie wizja świata tworzona jest w umyśle dziecka nie tylko dzięki jego możliwościom poznawczym, ale przede wszystkim dzięki inspirującym wpływom środowiska.

\section{Literatura}

Angrosino M. (2010), Badania etnograficzne i obserwacyjne. Warszawa, Wydawnictwo Naukowe PWN.

Anusiewicz J. (1992), Potoczność jako sposób doświadczania świata i jako postawa wobec świata. W: J. Anusiewicz, F. Nieckula (red.), Język a kultura, t. 5. Wrocław, Wydawnictwo Uniwersytetu Wrocławskiego.

Appleton K. (1997), Analysis and description of students' learning during science classes using a constructivist-based model, „Journal of Research in Science Teaching”, 34.

Bartmiński J. (2007), Językowe podstawy obrazu świata. Lublin, Wydawnictwo UMCS.

Bauman Z. (2008), Wspólnota. W poszukiwaniu bezpieczeństwa w niepewnym świecie. Kraków, Wydawnictwo Literackie.

Boniecka B. (2001), Definicje i eksplikacje dziecięce. W: S. Grabias (red.), Zaburzenia mowy. Lublin, Wydawnictwo UMCS.

Boniecka B., Grabias S. (red.) (2007), Potoczność a zachowania językowe Polaków. Lublin, Wydawnictwo UMCS.

Bruner. J. (2006), Kultura edukacji. Kraków, Universitas.

Feuerstein R., Klein P.S., Tannenbaum A.J. (red.) (1994), Mediated Learning Experience (MLE). Theoretical, Psychosocial and Learning Implications. London, Freund Publishing House Ltd.

Filipiak E. (2018), Cultural-historical theory by Lev S. Vygotsy (CHAT): strategies of studies on children's learning and development. From theory to change in practice (wystąpienie na I Symposium Developmental approach to education according to Lev S. Vygotsky, Bydgoszcz, 19-20 marca 2018)

Klus-Stańska D. (2010), Dydaktyka wobec chaosu pojęć i zdarzeń. Warszawa, Wydawnictwo Akademickie Żak.

Kravcov E., Kravcov G. (2018), Cultural-historical bases of creation of system of continuous education (wystąpienie na I Symposium Developmental approach to education according to Lev S. Vygotsky, Bydgoszcz, 19-20 marca 2018) 
Langacker R.W. (1995), Symboliczny charakter gramatyki. W: H. Kardela (red.), Wykłady z gramatyki kognitywnej. Lublin, Wydawnictwo UMCS.

Maćkiewicz J. (2000), Potoczne w naukowym - niebezpieczeństwa i korzyści. W: A. Dąbrowska, J. Anusiewicz (red.), Język a kultura, t. 13, Wrocław, Wydawnictwo Uniwersytetu Wrocławskiego.

McShane J. (2001), Cognitive Development: An Information Processing Approach. Oxford, Blackwell.

Mietzel G. (2003), Psychologia kształcenia. Praktyczny podręcznik dla pedagogów i nauczycieli. Gdańsk, GWP.

Rommetveit R. (1985), Language acquisition as increasing linguistic structuring of experience and symbolic behavior control. W: J.V. Wertsch (red.) Culture, communication and cognition: Vygotskian perspectives. Cambridge, Cambridge University Press.

Schaffer H.R. (1994), Epizody wspólnego zaangażowania jako kontekst rozwoju poznawczego. W: A. Brzezińska, G. Lutomski (red.), Dziecko w świecie ludzi i przedmiotów. Poznań, Wydawnictwo Zysk i S-ka.

Wood D. (2006), Jak dzieci ucza się i myśla. Spoleczne konteksty rozwoju poznawczego. Kraków, Wydawnictwo Uniwersytetu Jagiellońskiego. 